Research Article

\title{
Effectiveness of the Strategies Implemented in Sri Lanka for Controlling the COVID-19 Outbreak
}

\author{
K. K. W. H. Erandi $\left(\mathbb{D},{ }^{1}\right.$ A. C. Mahasinghe, ${ }^{1}$ S. S. N. Perera, ${ }^{1}$ and S. Jayasinghe ${ }^{2}$ \\ ${ }^{1}$ Research \& Development Centre for Mathematical Modelling, Department of Mathematics, University of Colombo, \\ Colombo 03, Sri Lanka \\ ${ }^{2}$ Department of Clinical Medicine, University of Colombo, Colombo 03, Sri Lanka
}

Correspondence should be addressed to K. K. W. H. Erandi; hasitha.erandi@yahoo.com

Received 2 June 2020; Revised 8 August 2020; Accepted 4 September 2020; Published 22 September 2020

Academic Editor: Qiankun Song

Copyright $\odot 2020$ K. K. W. H. Erandi et al. This is an open access article distributed under the Creative Commons Attribution License, which permits unrestricted use, distribution, and reproduction in any medium, provided the original work is properly cited.

\begin{abstract}
In order to bring the new coronavirus pandemic in the country under control, the government of Sri Lanka implemented a set of control strategies including social distancing, quarantine, lockdowns, travel restrictions, and isolation of villages. The aim of this study is to investigate the effectiveness of the overall control process with the aid of classical compartment models and network models. Our results indicate that the prevailing control strategies are effective with at least $50 \%$ contact rate reduction or with at least $40 \%$ isolation of the contact history of infected population.
\end{abstract}

\section{Introduction}

An outbreak of a novel coronavirus (COVID-19) was reported from Wuhan Province, China, in December 2019 [1, 2], causing numerous deaths and complications such as pneumonia and acute respiratory distress syndrome [3-5]. The infection rapidly spread to all parts of the globe and was declared a pandemic on $11^{\text {th }}$ March 2020 by the World Health Organization [6].

Sri Lanka reported the first case in a Chinese tourist on $27^{\text {th }}$ January 2020 and subsequently in a local person on $11^{\text {th }}$ March, 2020 [7]. Aimed at controlling the pandemic, the government enforced a strict strategy of case detection, identification of contacts, quarantine, travel restrictions, and isolation of small villages as well, changing the strategy in a timely manner, that has so far been successful in confining the epidemic to 2,810 cases as of $29^{\text {th }}$ July 2020 and no community case was reported in the country since $30^{\text {th }}$ April 2020. Figure 1 shows the variation of total cases and new cases reported up to $29^{\text {th }}$ July 2020 .

Though some attention has been paid to other control measures such as spraying disinfectants, aimed at destroying the virus, the major control strategies implemented in Sri Lanka was aimed at minimizing the human movement. It is noteworthy that this was not a strategy used in the country even during the multiple epidemics of dengue, though others have long exercised restricting the mobility to control infectious diseases [8]. However, with the emergence of the COVID-19 outbreak, strict measures were taken to minimize human mobility. On $20^{\text {th }}$ March, a nationwide curfew was imposed till $24^{\text {th }}$ March and it was further extended together with a strict ban on interdistrict travel. The curfew was a legal mechanism available to the newly elected government since parliament had been dissolved pending an election. Three populous districts of Colombo, Kalutara, and Gampaha were identified as high-risk zones. The main intention of the curfew was to implement a lockdown and minimize contacts with infected individuals and thereby reduce the growth rate of the epidemic.

Entry of the virus to the island nation was curtailed by closure of the airport and the ports together with the curfew. Extensive tracing was done of recent returnees from overseas (especially from China, Italy, and South Korea) [9]. Identified patients were transferred to designated infectious disease hospitals and potential contacts to more than 40 quarantine centers, which were developed within a very short period and opened by the Ministry of Defense. In addition, on $21^{\text {st }}$ April 2020, the government began repatriating citizens stranded abroad and quarantine them for a two-week time 


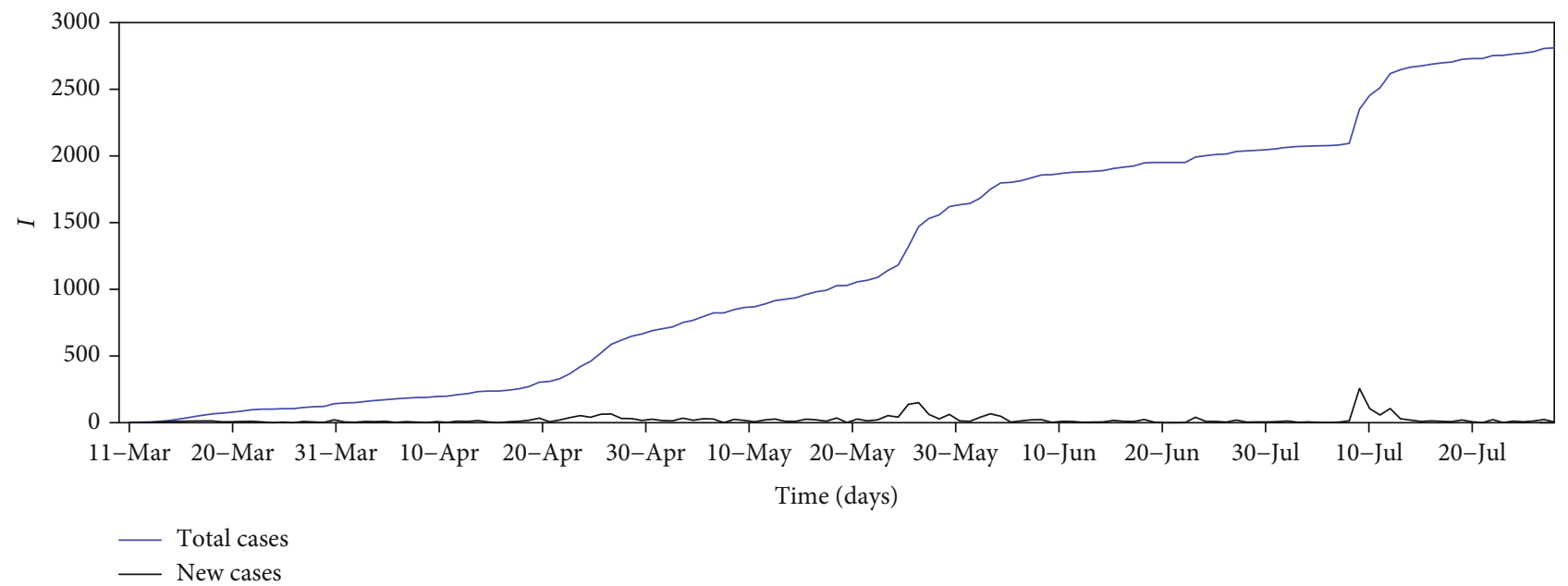

Figure 1: Reported COVID-19 cases from $11^{\text {th }}$ March 2020 to $29^{\text {th }}$ July 2020, Sri Lanka (source: Epidemiology Unit, Ministry of Health, Sri Lanka).

period. In another example of quarantine, a whole village was sealed and quarantined in that location because an identified patient was found to have moved around 26 households in a circumscribed village. Entry and exit from the village were banned, and they received free supplies and other amenities at the border. Starting from $26^{\text {th }}$ March, more than 16 villages or defined small urban areas were sealed for 2-4 weeks in the country to control the spread of the disease. Moreover, on $22^{\text {st }}$ April 2020, a sailor from Welisara Navy Camp was identified as a COVID-19-positive patient and immediately, the camp was quarantined with 4,000 people at the Navy Camp. Since many sailors were on leave when the disease was contracted, more than 6 villages were sealed off and around 1,300 people have been asked to self-quarantine.

Considering the progress of the control measures and the impact of the strict curfew to the economy of the country, the government has announced on $19^{\text {th }}$ April 2020 its decision to relax the nationwide curfew and to implement moderated travel restrictions by permitting interdistrict travels only to report for work and for essential service purposes. Further, on $11^{\text {th }}$ May 2020, the government had ordered partial opening of offices and businesses and the restrictions were further relaxed with a new set of rules. For an example, wearing a mask is mandatory in indoor and outdoor public spaces and public transport. The police and army personnel have been empowered to carefully scrutinize whether citizens are obeying with the rules. Moreover, the sanitary measures such as having wash basins and sanitizers outside the grocery stores and supermarkets for customers have been made compulsory and the supermarkets were instructed to use thermometers to check the temperatures of the customers before they enter the premises. The distances are marked in the counter queues to minimize the close contacts. Schools however started academic activities only for grades 5, 11, and 13 on $6^{\text {th }}$ June, and universities will continue online teaching and learning until further notice.

Almost all control strategies implemented in Sri Lanka were aimed at minimizing the human mobility; both the imposition and the relaxation of the curfew could be interpreted as changing the mobility rates in a certain way. From a policy perspective, it is relevant to know the extent of mobility that would be optimum to control the pandemic. This could be supported by reviewing the impact of mobility restrictions on the pattern of 254 reported cases up to $19^{\text {th }}$ April 2020 and comparing with the current situation. This would include the effects of curfew in some regions on other regions.

In order to review the impact of the control strategies implemented so far, we used the classical compartment models in epidemiology to model the transmission of COVID-19 in the three main districts. The restrictions imposed of human movement were incorporated by moderating the compartment model accordingly, by parametrizing contact rate and adding interdistrict travel. Then, we investigated the impact of relaxing the curfew by considering how the disease could be transmitted through the epidemiological network created by interregional transport.

\section{Materials and Methods}

In order to examine the transmission of COVID-19, we adopted the Susceptible-Exposed-Infectious-Recovered (SEIR) model [10] with control measures applied to the high-risk zones in the country. Since the incubation period for the disease is 2-14 days as reported, there is a high possibility of transmission prior to the onset of symptoms and without showing symptoms [11], which justifies the adoption of the SEIR model. In the classical SEIR model, a population of size $N_{i}$ in the $i$ th region is divided into susceptible $\left(S_{i}\right)$, exposed $\left(E_{i}\right)$, infected $\left(I_{i}\right)$, and recovered $\left(R_{i}\right)$ components. We extended the model by including an extra compartment as hospitalized $\left(H_{i}\right)$. This included all those entering hospitals and quarantine centers. The susceptible class consists of individuals who can possibly get infected by the disease. If the susceptible person is exposed to the virus, the individual is moved to the exposed compartment at the rate of $\beta_{i}$. Let $\alpha$ be the 
transition rate of the exposed individuals to the infected class. Infected individuals, those who are hospitalized, are moved to the newly added compartment hospitalized at the rate of $h$. Infected persons in compartments $I_{i}$ and $H_{i}$ are moved to the recovered compartment after the infectious period $\gamma^{-1}$, and the persons in the recovered class are assumed to have permanent immunity against the disease.

For this study, it is assumed that the mean infectious period is $\gamma^{-1}=10.25$ days [12]. Since COVID-19 virus load in the upper respiratory tract peaks within the first week of infection and transmission of the disease can occur 1-3 days before symptom onset, it is assumed that the exposed person is infectious and able to transmit the virus to another person after 5 days of the latent period $\left(\alpha^{-1}\right)[13,14]$. In order to scale $\beta_{i}$, we used fminsearch in MATLAB.

Let $L_{i j}$ denotes the percentage of daily travels from district $i$ to $j$. We assumed that the percentage of daily inbound and outbound travel frequency to Colombo district is $15 \%$ and the percentage of daily travel frequency between Kalutara district and Gampaha district is 5\%. Moreover, we introduced a parameter contact rate, symbolized by $c$, to quantify the degree of social distancing. We considered $c$ a normalized version of such a parameter; therefore, the values of $c$ lie between 0 and 1 , and the case $c=1$ is associated with a situation where no control measures are taken. A varying $c$ represents the changing levels of control measures, and it is assumed that the contact rate within each stage is relatively stable.

In order to investigate the impact of relaxing the curfew to other regions, we considered an epidemiological network in the form of a weighted graph, of which the vertices represent regions and the edges their interconnections. Vertex weights were assigned proportional to the reported COVID-19 in the regions, and the edges were weighted by considering the level of interconnections, once the travel is permitted. It was assumed the interregional travel after relaxing the curfew resembles the travel before the lockdowns. Accordingly, highly vulnerable regions were identified, which need to be paid more attention when future control measures are designed by Sri Lankan health planners.

2.1. Transmission before the Lockdowns. We first examined the transmission dynamics before the imposition of curfew. This situation is governed by the epidemic model with neither control measures nor quarantine. As stated previously, we consider the transmission in each district; the rate change of susceptible $\left(S_{c}\right)$, exposed $\left(E_{c}\right)$, infected $\left(I_{c}\right)$, recovered $\left(R_{c}\right)$, and hospitalized $\left(H_{c}\right)$ populations in Colombo district can be described by the following set of differential equations, where similar sets of differential equations can be built for Kalutara $(k)$ and Gampaha $(g)$ :

$$
\begin{aligned}
\frac{d S_{c}}{d t}= & -c \beta_{c} \frac{S_{c}}{N_{c}}\left(I_{c}+I_{k} L_{(k, c)}+I_{g} L_{(g, c)}\right) \\
& -S_{c}\left(L_{(c, k)}+L_{(c, g)}\right) \\
& +S_{k} L_{(k, c)}+S_{g} L_{(g, c)},
\end{aligned}
$$

$$
\begin{aligned}
\frac{d E_{c}}{d t}= & c \beta_{c} \frac{S_{c}}{N_{c}}\left(I_{c}+I_{k} L_{(k, c)}+I_{g} L_{(g, c)}\right) \\
& -\alpha E_{c}-E_{c}\left(L_{(c, k)}+L_{(c, g)}\right) \\
& +E_{k} L_{(k, c)}+E_{g} L_{(g, c)}, \\
\frac{d I_{c}}{d t}= & \alpha E_{c}+I_{k} L_{(k, c)}+I_{g} L_{(g, c)}-\gamma I_{c} \\
& -h I_{c}-I_{c}\left(L_{(c, k)}+L_{(c, g)}\right), \\
\frac{d R_{c}}{d t}= & \gamma\left(I_{c}+H_{c}\right)+R_{k} L_{(k, c)}+R_{g} L_{(g, c)} \\
& -R_{c}\left(L_{(c, k)}+L_{(c, g)}\right), \\
\frac{d H_{c}}{d t}= & h I_{c}-\gamma H_{c} .
\end{aligned}
$$

2.2. Transmission during the Lockdown Period. The situation during the lockdown which started from $20^{\text {th }}$ March was examined under three stages. The first stage is the period that starts from the first reported incidence to the date a curfew to a certain extent was imposed. Naturally, transmission dynamics has changed from this particular day. Thus, the contact rate reduced from this point on. To determine the contact rate reduction from $20^{\text {th }}$ March, we considered the difference between actual infected data and simulation data for several $c$ values, as depicted in Figure 2, and based on the results, $c$ was set to be 0.8 from $20^{\text {th }}$ March. This period is considered the second stage. The third stage was when a strict interdistrict travel ban was imposed from $24^{\text {th }}$ March onwards. Thus, the parameters needed to be changed again from this point on: that is, $L_{i, j}=0$ for all districts.

Also, we considered that the contact tracing took place during this period. During the lockdowns, it was more convenient for the authorities to find the contact history of the infected individuals, and much progress seemed to be made in this regard. Based on the findings, the high-risk village was sealed in Kalutara district on $26^{\text {th }}$ March. Subsequently, several other small geographical regions were sealed off. As a consequence, the number of self-quarantined individuals increased from $26^{\text {th }}$ March onwards. Hence, we added a new compartment named quarantined $\left(Q_{i}\right)$ for each district $i$ in the existing model. The compartment $Q_{i}$ consists of exposed individuals identified by contact tracing and susceptible individuals living in the sealed-off villages. By enforcing contact tracing, $q$ percentage of individuals exposed to the virus is quarantined. The quarantined individuals leave this compartment at a rate of $\lambda$ and move to the hospitalized compartment with a proportion $b$, if confirmed to be infected by COVID-19; otherwise, they go back to the susceptible class after the quarantined period of 14 days. The extended model that represents this scenario is expressible as follows:

$$
\frac{d S_{c}}{d t}=-\left(c \beta_{c}+c\left(1-\beta_{c}\right) q\right) \frac{S_{c}}{N_{c}} I_{c}
$$




$$
\begin{aligned}
& \frac{d E_{c}}{d t}=c \beta_{c}(1-q) \frac{S_{c}}{N_{c}} I_{c}-\alpha E_{c}, \\
& \frac{d I_{c}}{d t}=\alpha E_{c}-\gamma I_{c}-h I_{c}, \\
& \frac{d R_{c}}{d t}=\gamma\left(I_{c}+H_{c}\right), \\
& \frac{d H_{c}}{d t}=h I_{c}-\gamma H_{c}+\lambda b Q_{c}, \\
& \frac{d Q_{c}}{d t}=c \beta_{c} q \frac{S_{c}}{N_{c}} I_{c}+c\left(1-\beta_{c}\right) q \frac{S_{c}}{N_{c}} I_{c}-\lambda Q_{c} .
\end{aligned}
$$

To analyze the effectiveness of physical distancing, we performed a sensitivity analysis on the parameter $c$ and compared the simulation results with actual reported data.

2.3. Transmission after Relaxing the Lockdown. From $20^{\text {th }}$ April, the transmission dynamics of the disease changed again, as the government decided to relax the nationwide curfew. During this period, the curfew was effective only between 8:00 pm and 5:00 am and 50\% of the workforce in state institutions were required to report to work. Travel between districts was permitted for purposes of employment or essential needs. Hence, we changed $L_{i j}$ values from $20^{\text {th }}$ April as the percentage of daily inbound and outbound travel frequency to Colombo district is $7.5 \%$ and the percentage of daily travel frequency between Kalutara district and Gampaha district is $2.5 \%$. In addition, since all the citizens are ordered to follow the new set of rules and wearing face masks and other prevention strategies reduce the transmission risk by more than $50 \%$, from $20^{\text {th }}$ April, the transmission rate is reduced by $50 \%[15,16]$.

Moreover, to investigate the impact of curfew relaxation on each province in Sri Lanka, we considered the epidemiological network of provinces and the extended model for province $i$ can be formulated as follows:

$$
\begin{aligned}
\frac{d S_{i}}{d t}= & -\left(c \beta_{i}+c\left(1-\beta_{i}\right) q\right) \frac{S_{i}}{N_{i}}\left(I_{i}+\sum_{j \neq i} L_{j i} I_{j}\right) \\
& +\sum_{j \neq i}\left(L_{j i} S_{j}-L_{i j} S_{i}\right)+\lambda(1-b) Q_{i}, \\
\frac{d E_{i}}{d t}= & c \beta_{i}(1-q) \frac{S_{i}}{N_{i}}\left(I_{i}+\sum_{j \neq i} L_{j i} I_{j}\right) \\
& +\sum_{j \neq i}\left(L_{j i} E_{j}-L_{i j} E_{i}\right)-\alpha E_{i}, \\
\frac{d I_{i}}{d t}= & \alpha E_{i}+\sum_{j \neq i}\left(L_{j i} I_{j}-L_{i j} I_{i}\right)-\gamma I_{i}-h I_{i}, \\
\frac{d R_{i}}{d t}= & \sum_{j \neq i}\left(L_{j i} R_{j}-L_{i j} R_{i}\right)+\gamma\left(I_{i}+H_{i}\right), \\
\frac{d H_{i}}{d t}= & h I_{i}-\gamma H_{i}+\lambda b Q_{i},
\end{aligned}
$$

$$
\frac{d Q_{i}}{d t}=\left(c \beta_{i} q+c\left(1-\beta_{i}\right) q\right) \frac{S_{i}}{N_{i}}\left(I_{i}+\sum_{j \neq i} L_{j i} I_{j}\right)-\lambda Q_{i} .
$$

2.4. More Consequences of Relaxing. When the curfew was relaxed, public transport was allowed and the decision was questioned by several parties and was a subject of severe debates. Strict social distancing was followed in the country during the curfew, even in the waiting lines at chemists (which were opened to supply medicines during the curfew), supervised by the security forces. However, once public transport was made available, it was observed that the distancing was not followed. Therefore, the risk of the virus being transmitted through the transportation network should not be ignored by the health planners.

Furthermore, it is important to examine the impact of public transport to the transmission of the virus. Assuming the public transport services operate at prevailing conditions, we determined which regions are most vulnerable, by considering a network model, of which the vertices represent regions and the edges their interconnections, weighted by numbers proportional to the number of public passenger vehicles available in those routes. Following [17], we too adopted the closeness centrality, defined by Equation (4), in order to measure the vulnerability of a province.

$$
C C_{i}=\frac{\sum_{j \neq i} v_{j}}{\sum_{j \neq i} w_{i j} v_{j}},
$$

where $v_{j}$ denotes the total number of infected population as a fraction of total population in the $j$ th province and $w_{i j}$ denotes the interconnection between province $i$ and $j$ in terms of human mobility.

We referred to the COVID-19 situation reports available from the Epidemiology Unit, Department of Health, Sri Lanka [7]. We used the average number of closed contacts of reported infectious as the initial exposed number for the model simulation and assumed all of them were reported from Colombo district. That is, $I_{c}=1$ and $E_{c}=26$ at $t=0$. In order to solve the developed model numerically, the fourth-order Runge-Kutta method was used with MATLAB. Table 1 represents the parameter values used in the model simulation.

\section{Results and Discussion}

Figures 3-5 illustrate the comparison of actual data and estimated infected population for different contact rates in Colombo, Kalutara, and Gampaha districts, respectively. There is a discrepancy between the actual data and simulation results in Figures 3-5. As stated in the previous section, we used fminsearch in MATLAB and set up the $\beta_{i}$ for each district $i$. Therefore, each district obtained nonidentical initial transmission rate values. Not surprisingly, the lowest $\beta_{i}$ value was obtained for Colombo district, the most populated district in the country, and the highest $\beta_{i}$ value for Kalutara district, the least populated district among the considered districts. 


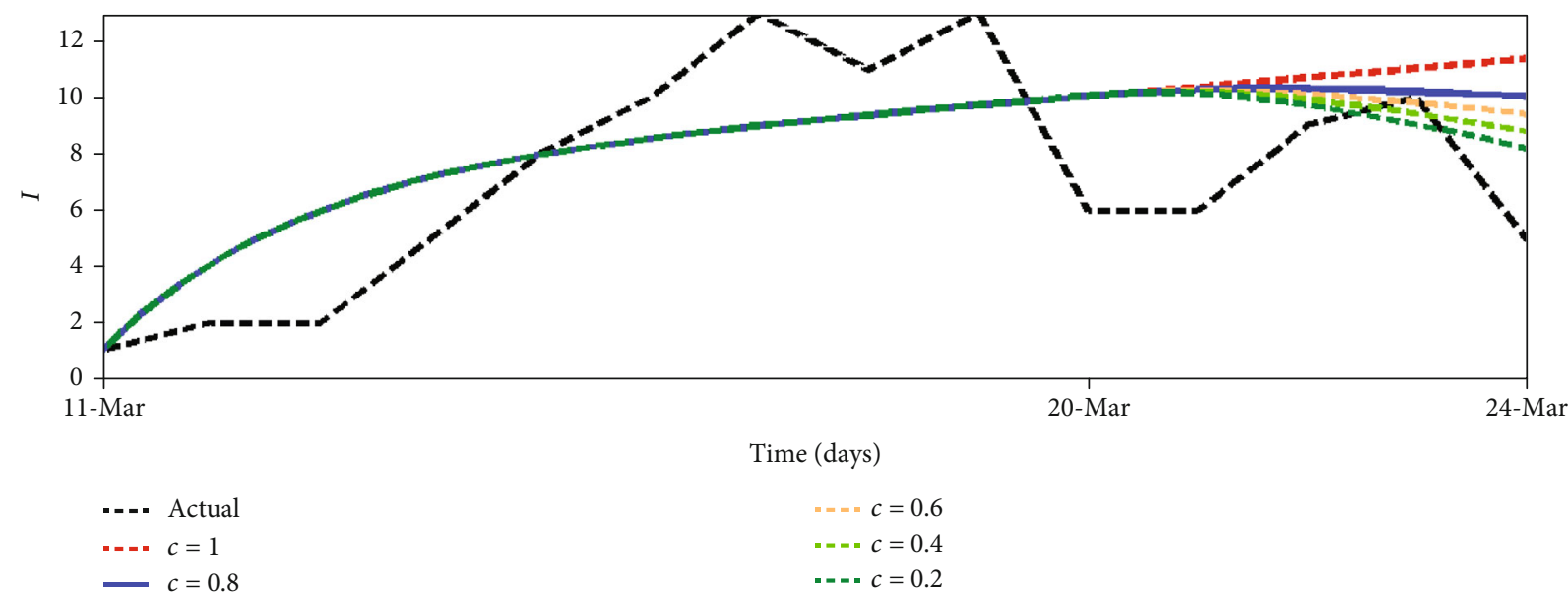

FIgURe 2: Comparison of actual infected data and simulation results for different contact rates in Sri Lanka from $20^{\text {th }}$ March to $24^{\text {th }}$ March.

TABLE 1: Descriptions and values of all parameters used in the model simulation.

\begin{tabular}{lccc}
\hline Parameter & Definition & Value & Reference \\
\hline$\beta_{c}$ & Transmission rate for Colombo district & 0.175 & Estimated \\
$\beta_{k}$ & Transmission rate for Kalutara district & 0.49 & Estimated \\
$\beta_{g}$ & Transmission rate for Gampaha district & 0.345 & Estimated \\
$\gamma^{-1}$ & Mean infectious period & 10.25 days & {$[12]$} \\
$\alpha^{-1}$ & Latent period & 5 days & {$[13]$} \\
$h$ & Hospitalization rate & 0.5 & Estimated \\
$\lambda^{-1}$ & Quarantined period & 14 days & {$[18]$} \\
$b$ & Hospitalization rate from quarantine centers & 0.01 & Estimated \\
\hline
\end{tabular}

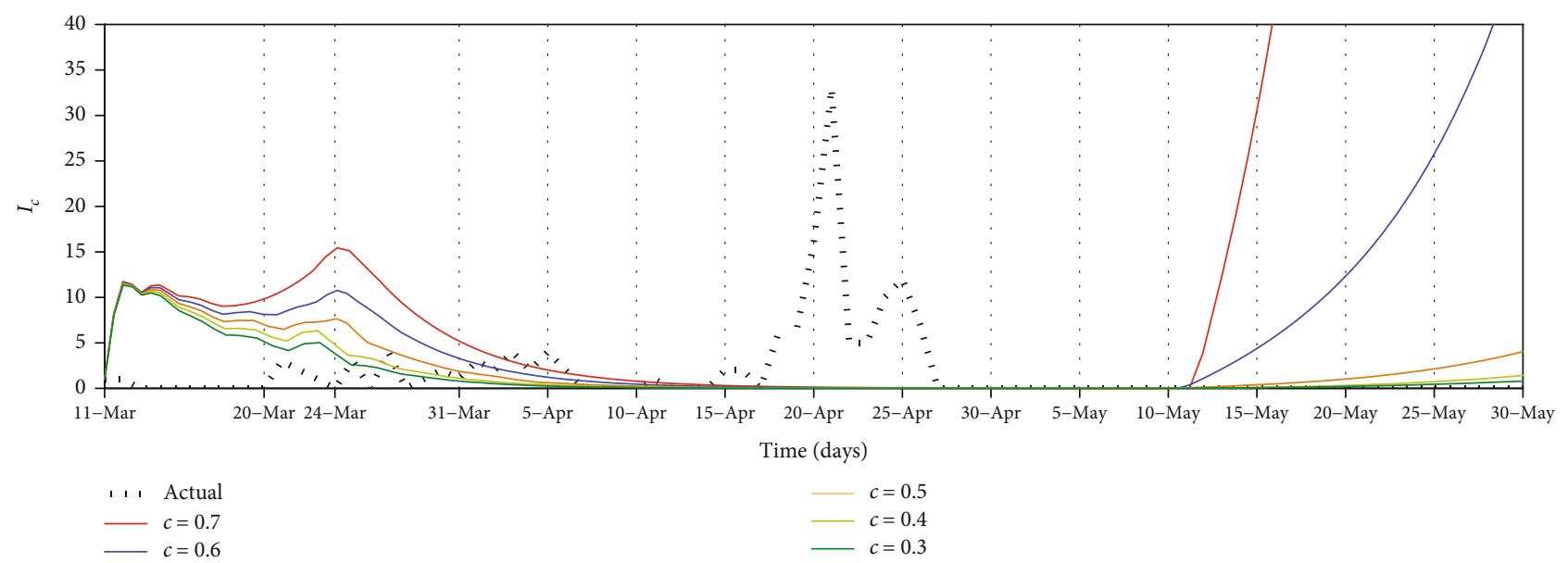

FIgURE 3: Comparison of actual infected data and simulation results for different contact rate values in Colombo district.

Therefore, the contact rate variation behaves differently for each province; hence, the dynamical behaviour of the infected population for different districts is significantly different as shown by Figures 3-5.

It is clear from the simulation results in Figures 4 and 5 that individuals in Kalutara and Gampaha districts get infected, even without any initially infected or exposed per- sons in the district. This indicates the significance of interdistrict mobility in the transmission of disease.

To learn about the nationwide disease transmission, we simulated the model for the entire country by changing model parameters and compared the simulation results with the reported infected data. Figure 6 illustrates the comparison of actual infected data and simulation results, and 


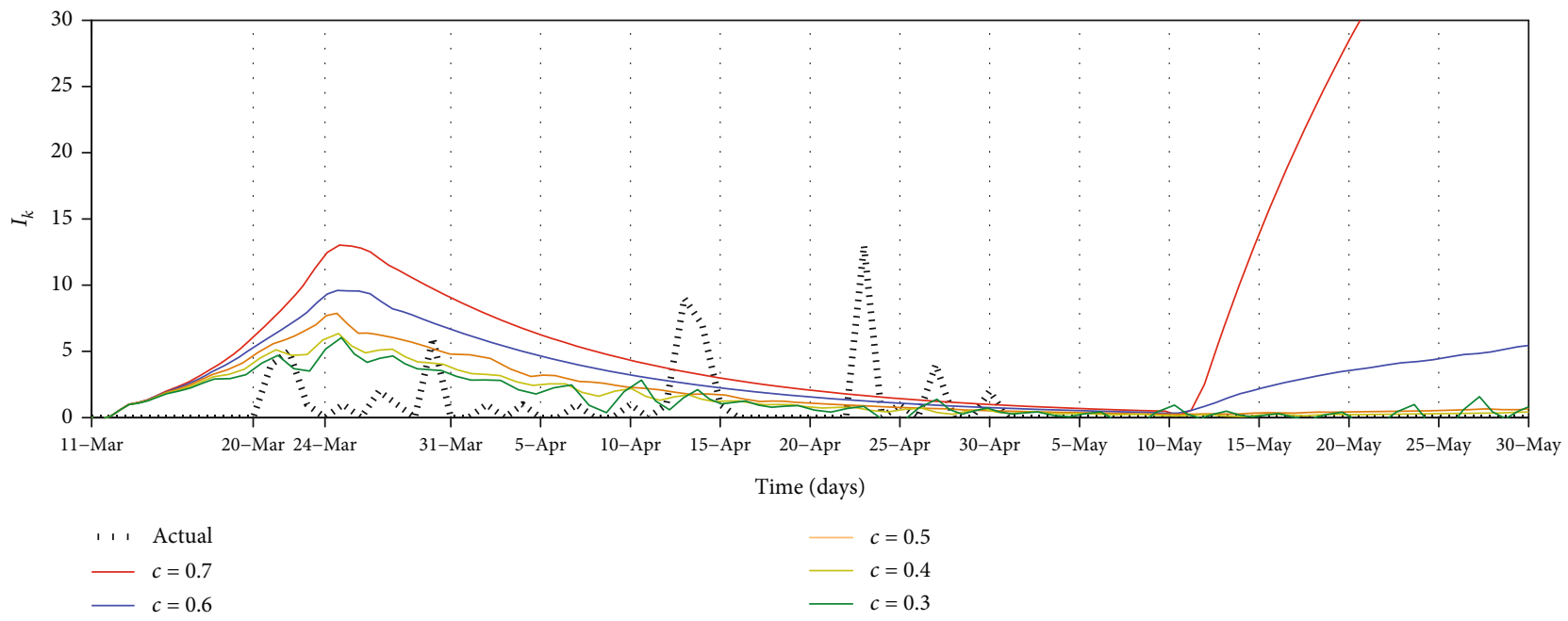

Figure 4: Comparison of actual infected data and simulation results for different contact rate values in Kalutara district.

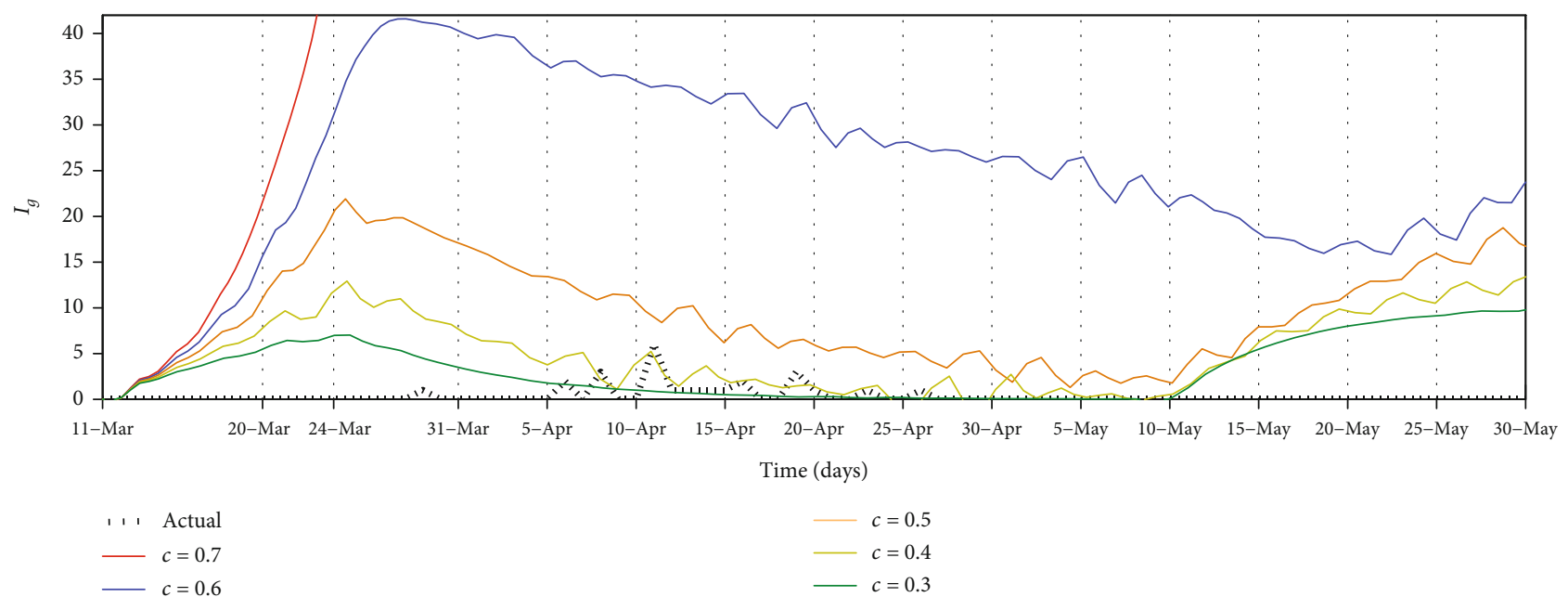

FIGURE 5: Comparison of actual infected data and simulation results for different contact rate values in Gampaha district.

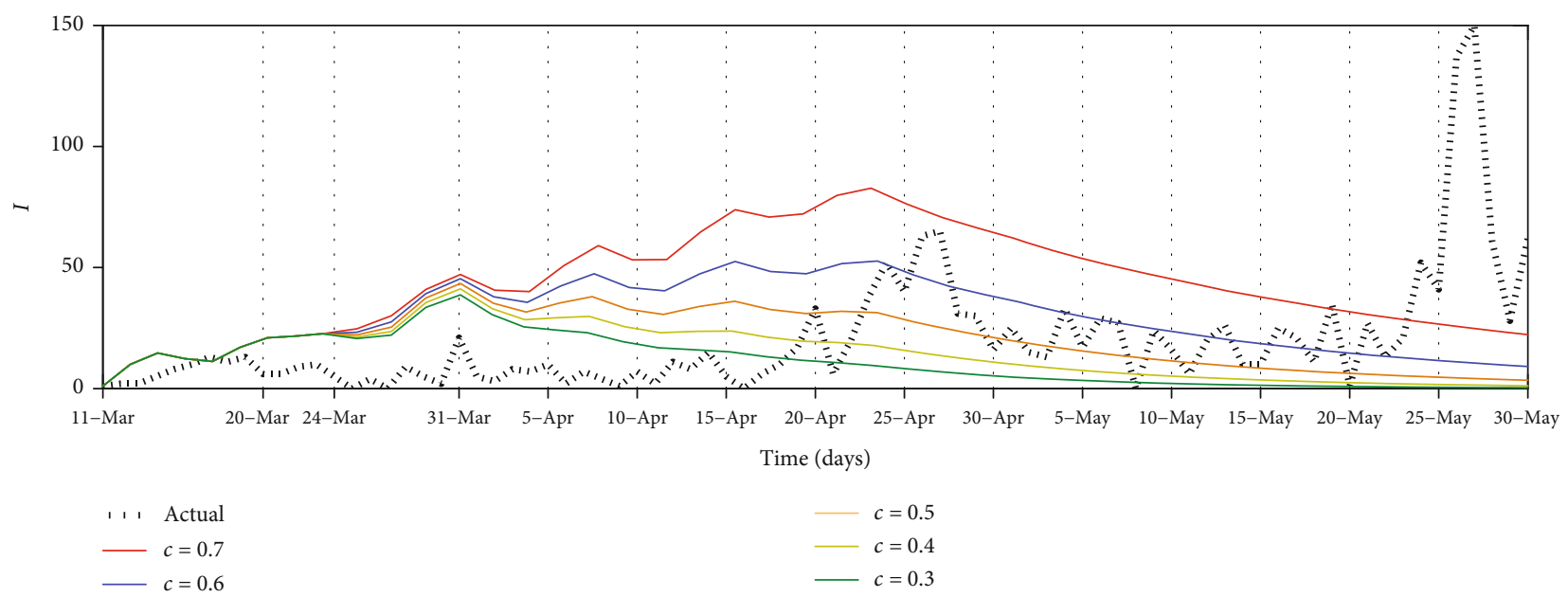

Figure 6: Comparison of actual infected data and simulation results for different contact rate values in Sri Lanka. 


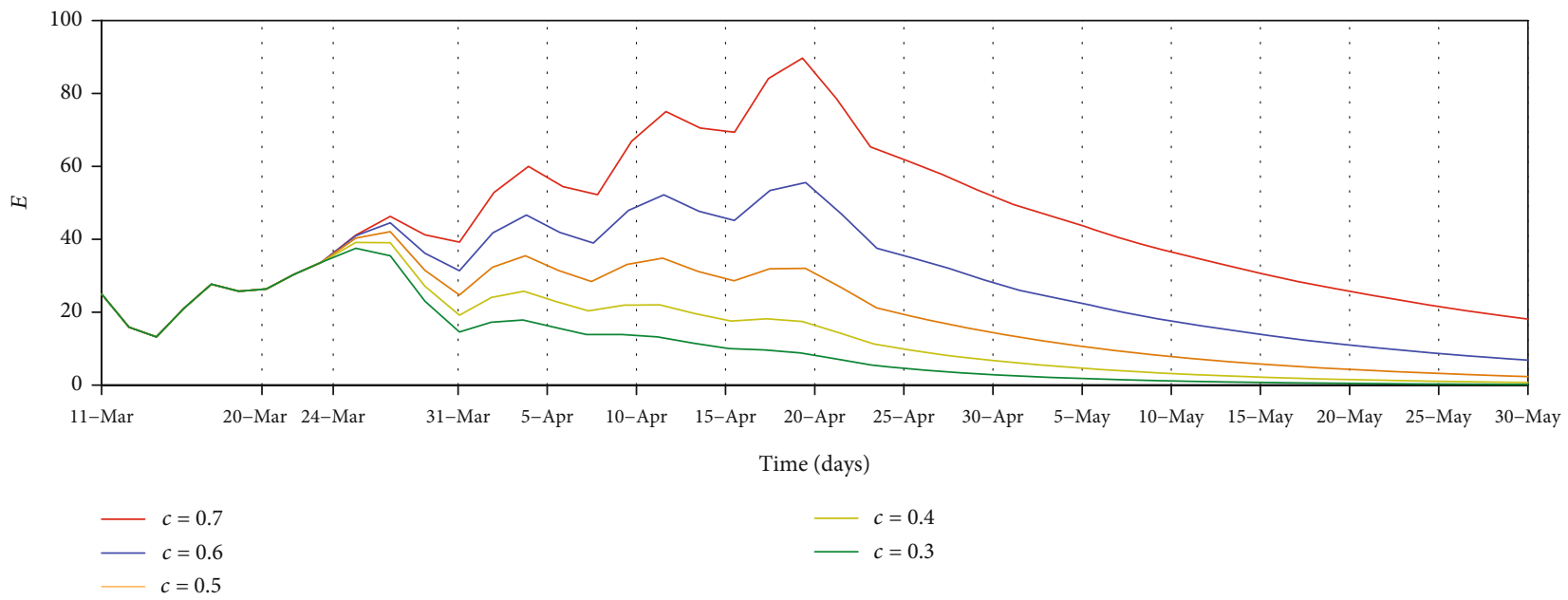

FiguRE 7: Estimated exposed population for different contact rate values in Sri Lanka.

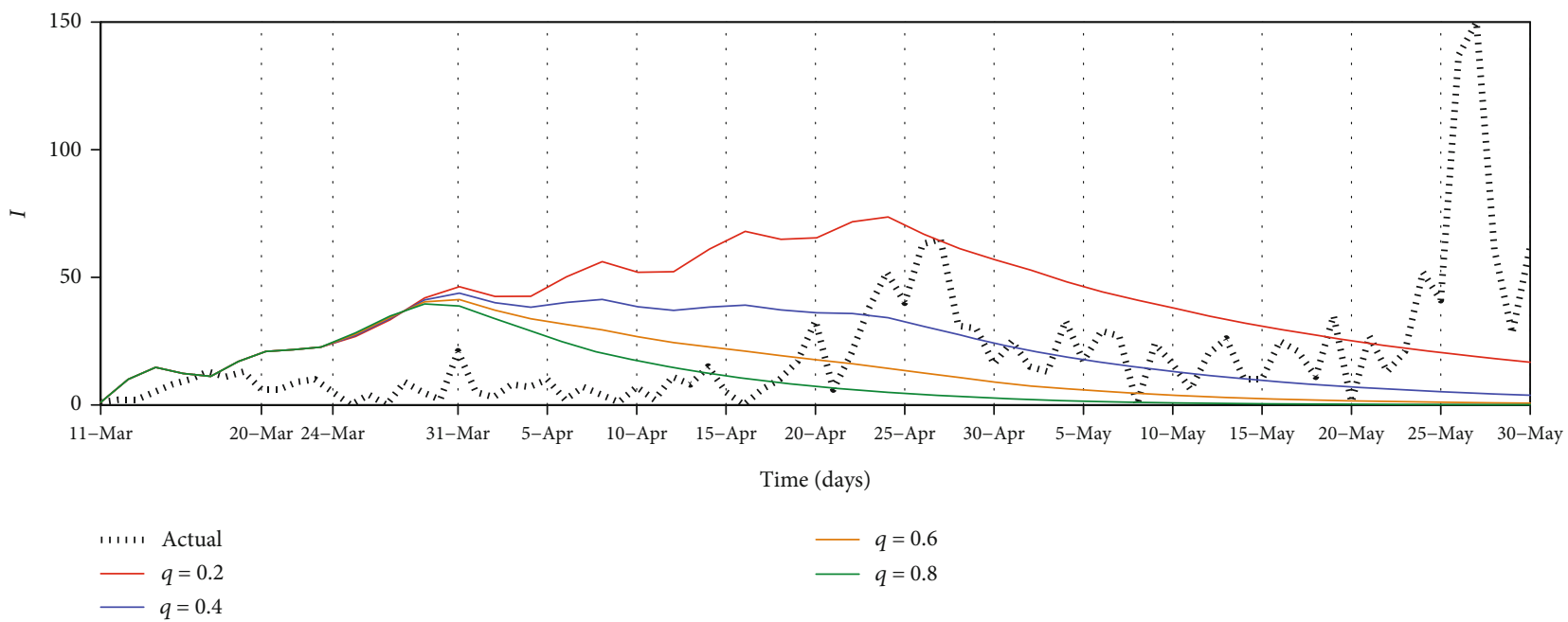

FIgURE 8: Comparison of actual infected data and simulation results for different quarantine values in Sri Lanka.

Figure 7 represents the estimated exposed population in Sri Lanka for different contact rate values. From Figure 6, it can be observed that a significant number of cases were after $30^{\text {th }}$ April and according to the Epidemiological Unit data, all of them were reported from quarantine centers.

Computational results for several contact rate values suggest that the currently practising control strategies would be beneficial if the contact rate is reduced by not less than $50 \%$. Moreover, it can be observed that the number of infected population could be reduced by increasing the number of control strategies.

In addition, to determine the effect of contact tracing and quarantine on the control of the spread of COVID-19, we performed a sensitivity analysis on parameter $q$. For the simulation, we assumed that contact rate is a constant value $(c=0.8)$ from $24^{\text {th }}$ March. Figure 8 illustrates the comparison of actual infected data and simulation results for different quarantined percentage in entire country, and the simulation results indicate that the control of the disease spread could be done by tracing not less than $40 \%$ of the contact history of the infected individual and quarantining them.

Considering the less chances of getting admitted to a hospital and the possibility of having unidentified cases in the country cannot be ruled out in this context. According to the data of Epidemiological Unit, Sri Lanka, 2/3 of the infections have no symptoms. In this sense, confirmed cases are only a fraction of the total infected population. Therefore, we believe that the actual number of infectious persons is not exactly the same as the number of reported cases on that day. According to recent studies $[19,20]$ and WHO reports [6], $50 \%-80 \%$ of infections are mild or asymptomatic. From Figure 9 , it can be observed that the cumulative number of reported infectious cases range between $1 / 2$ and $3 / 4$ of estimated infectious cases up to $25^{\text {th }}$ April.

Recall that after $25^{\text {th }}$ April, most of the identified cases were from the navy Welisara Navy Camp cluster and most of them were asymptomatic cases. Therefore, after $25^{\text {th }}$ April, difference between the number of reported cases and actual 


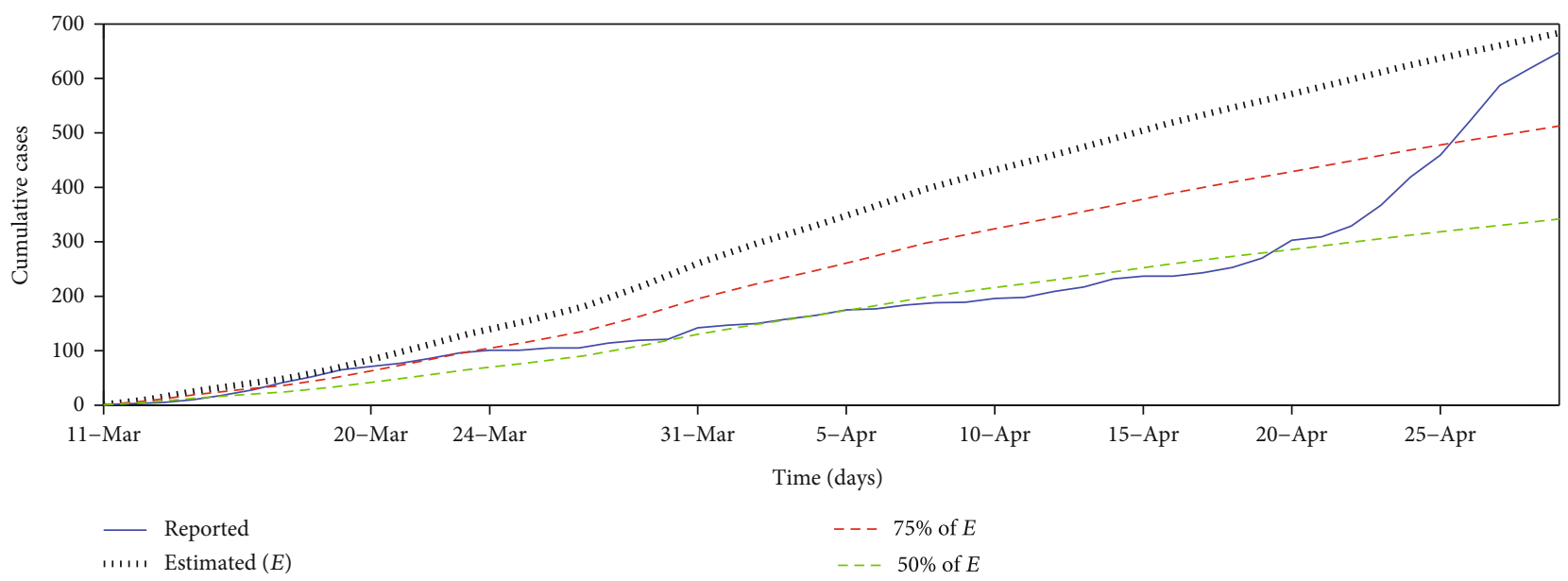

FIGURE 9: Comparison of actual infected data and simulation results for different percentage of $\rho$ in Sri Lanka ( $\rho$ is the ratio of symptomatic to total infectious cases).

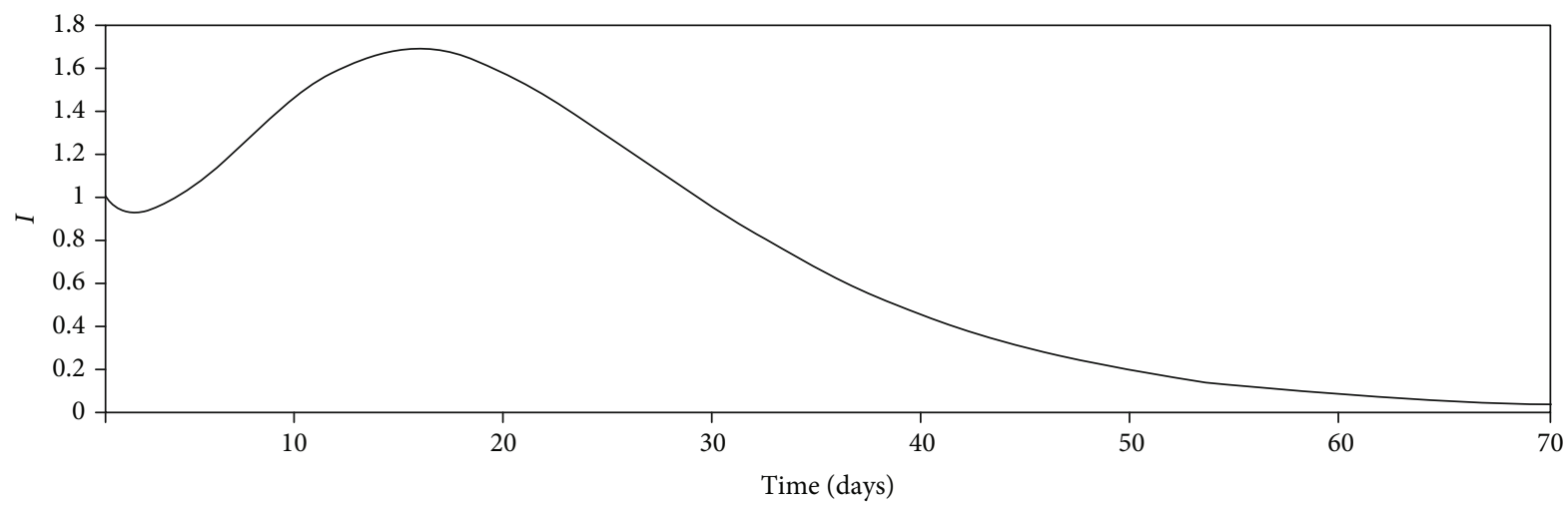

FIGURE 10: Estimated infected population in a household (assuming the average number of persons in a Sri Lankan household to be 5).

infectious cases was reduced. Since no community case was reported in the country after $30^{\text {th }}$ April 2020, we have done the comparison for the period from $11^{\text {th }}$ March to $30^{\text {th }}$ April 2020.

After identifying the COVID-19-positive patient who is a sailor from Welisara Navy Camp, the camp was quarantined with immediate effect with sailors and their families. When the disease was contracted, many sailors were on leave and immediately, all sailors were recalled to the camp and the contact history of each sailors identified. In such a situation, some villages or small regions have been sealed and residents have been asked to be self-quarantined based on the contact history of infected individuals. Once the high-risk regions are identified, the next immediate problem is how long these areas need to be isolated. Assuming an ideal self-quarantine, it is possible to forecast the transmission of the disease. Let $t=1$ be the time the self-quarantine started. In an idealized situation, each person is confined to households. Assuming the average number of persons in a household in Sri Lanka is 5 [21], we applied the classical SEIR model to infected households to find the approximate maximum time this household gets infected. According to Figure 10, the number of infected population in a household is less than 1 after 30 days and nearly zero in 60 days. Therefore, we suggest to seal off houses with exposed individuals or villages for a minimum 30-day to maximum 60-day duration.

In addition, our computational results on the potential consequences of lifting the travel restrictions indicate the possibility the disease being transmitted to some provinces where yet only a few infected persons have been reported. Figure 11 illustrates the impact of curfew relaxation on each province in Sri Lanka as of $19^{\text {th }}$ April, and the provinces in Sri Lanka with their closeness centrality measures are presented in Table 2. Comparing the total cases up to $31^{\text {th }}$ May with the rank values, it can be observed that other than the Southern province, all other provinces follow the closeness centrality ranks. A similar analysis with interdistrict travel data would provide more insights on how the disease will be transmitted through the transportation network. Thus, the authorities can make decisions on controlling the transport network or allocating provincial or district-wise resources during a pandemic situation.

\section{Conclusion}

The government of Sri Lanka has implemented a sequence of control measures including nationwide curfew, interdistrict travel restriction, and lockdown of high-risk villages to 


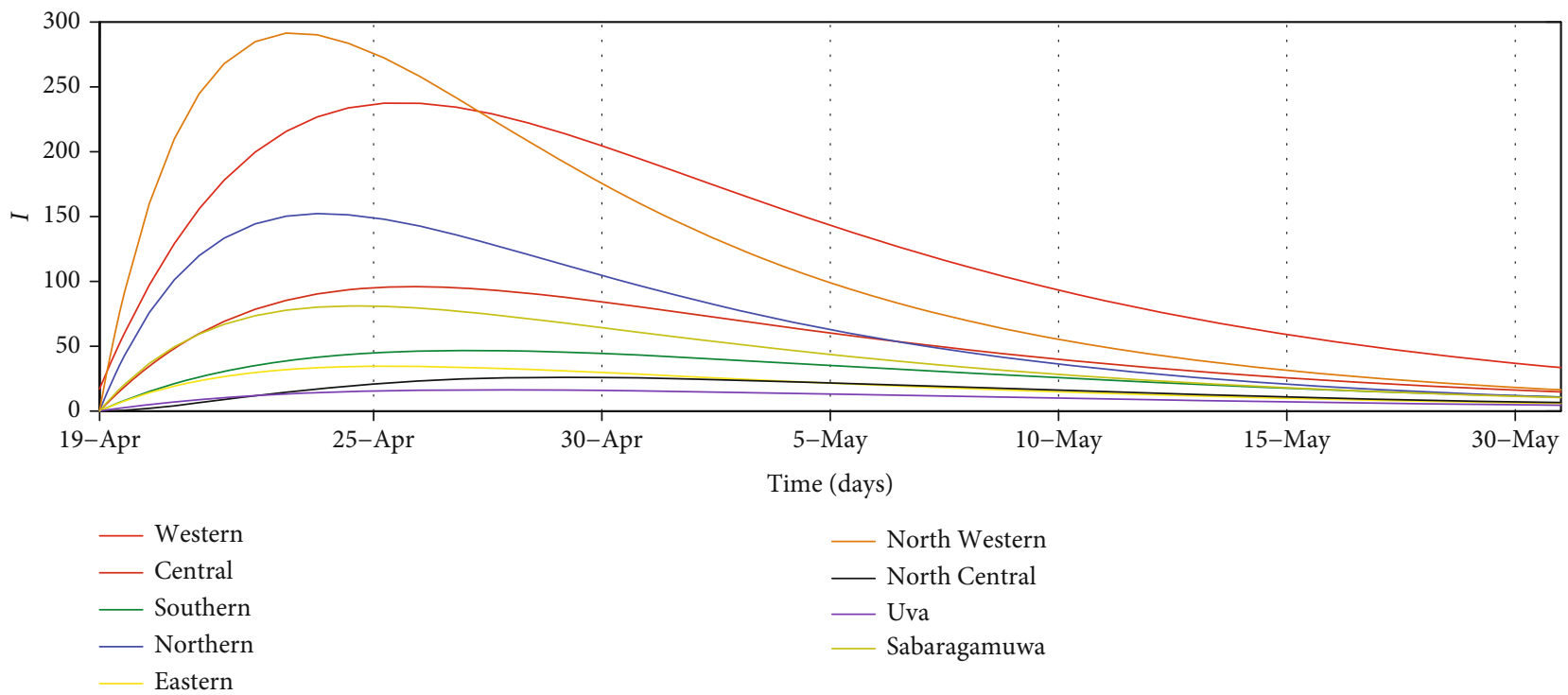

FIGURE 11: Estimated provincial infected population based on interprovincial mobility.

TABLE 2: Total reported COVID-19 cases (up to $19^{\text {th }}$ April 2020 and up to $31^{\text {st }}$ May 2020) and normalized closeness centrality results with ranking of the provinces in Sri Lanka.

\begin{tabular}{lcccc}
\hline Province & $\begin{array}{c}\text { Total } \\
\text { cases } \\
(19 / 04)\end{array}$ & $\begin{array}{c}\text { Normalized } \\
\text { closeness } \\
\text { centrality }\end{array}$ & Rank & $\begin{array}{c}\text { Total } \\
\text { cases } \\
(31 / 05)\end{array}$ \\
\hline Western & 154 & 0.1095 & 1 & 220 \\
North & 37 & 0.1119 & 2 & 46 \\
Western & 3 & 0.1861 & 3 & 3 \\
Southern & 7 & 0.2314 & 4 & 15 \\
Central & 8 & 0.2460 & 5 & 9 \\
Sabaragamuwa & 0 & 0.4690 & 6 & 3 \\
North Central & 7 & 0.6267 & 7 & 7 \\
Northern & 1 & 0.7239 & 8 & 5 \\
Uva & 3 & 1.0000 & 9 & 3 \\
Eastern & & & &
\end{tabular}

reduce the growth rate of the COVID-19 pandemic. In this work, we proposed a conceptual model based on the classical SEIR model to describe and analyze the effectiveness of the control strategies implemented in Sri Lanka under five different stages.

The computational results over several contact rate values suggest that the reduction of contact rate by not less than $50 \%$ would make the outbreak easier to control and the results over several quarantine percentage values suggest that tracing not less than $40 \%$ of the contact history of the infected individual and quarantining them could contribute to reducing the overall size of the COVID-19 outbreak. Assuming an ideal situation for self-quarantine, we implemented the simple SEIR model over household data to estimate the approximate time period for the quarantine process and the results indicated that the approximate maximum time the household should be quarantined is 60 days.
In addition, the human mobility inside the country has to be regulated or restricted, in order to stop the disease being transmitted.

\section{Data Availability}

COVID-19 data can be retrieved via Epidemiology Unit, Ministry of Health, Sri Lanka, available at http://www.epid.gov.lk/ web/index.php?option=com_content\&view=article\&id= 225\&Itemid=518\&lang=en, and mobility data can be retrieved via National Transport Commission, Sri Lanka, available at https://www.ntc.gov.lk/corporate/pdf/statistics\%202015.pdf.

\section{Conflicts of Interest}

The authors declare that they have no conflicts of interest.

\section{Acknowledgments}

This work was partly supported by the National Science Foundation grant number RPHS/2016/D/05.

\section{References}

[1] C. Huang, Y. Wang, X. Li et al., "Clinical features of patients infected with 2019 novel coronavirus in Wuhan, China," The Lancet, vol. 395, no. 10223, pp. 497-506, 2020.

[2] Z. Wu and J. M. McGoogan, "Characteristics of and important lessons from the coronavirus disease 2019 (COVID-19) outbreak in China," Jama, vol. 323, no. 13, 2020.

[3] C. C. Lai, T. P. Shih, W. C. Ko, H. J. Tang, and P. R. Hsueh, "Severe acute respiratory syndrome coronavirus 2 (SARSCoV-2) and coronavirus disease-2019 (COVID-19): the epidemic and the challenges," International journal of antimicrobial agents, vol. 55, no. 3, article 105924, 2020.

[4] H. A. Rothan and S. N. Byrareddy, "The epidemiology and pathogenesis of coronavirus disease (COVID-19) outbreak," Journal of autoimmunity, vol. 109, article 102433, 2020. 
[5] Y. Y. Zheng, Y. T. Ma, J. Y. Zhang, and X. Xie, "COVID-19 and the cardiovascular system," Nature Reviews Cardiology, vol. 17, no. 5, pp. 259-260, 2020.

[6] World Health Organization (WHO), Coronavirus disease 2019 (COVID-19): situation report, vol. 51, 2020.

[7] E. Unit, "Ministry of health, Sri Lanka. Coronavirus disease 2019 (COVID-19)-situation report- 19.04.2020-10.00am," 2020.

[8] P. Bajardi, C. Poletto, J. J. Ramasco, M. Tizzoni, V. Colizza, and A. Vespignani, "Human mobility networks, travel restrictions, and the global spread of 2009 h1n1 pandemic," PloS one, vol. 6, no. 1, article e16591, 2011.

[9] E. Unit, "Follow up of Sri Lankan nationals and other foreign nationals returning from high risk areas," 2020, https://www .epid.gov.lk/web/images/pdf/circulars/corona-virus/followupof-sri-lankannationals-and-other-foreign-nationals.pdf.

[10] L. J. Allen, F. Brauer, P. Van den Driessche, and J. Wu, Mathematical epidemiology, vol. 1945, Springer, 2008.

[11] S. M. Moghadas, M. C. Fitzpatrick, P. Sah et al., "The implications of silent transmission for the control of COVID-19 outbreaks," Proceedings of the National Academy of Sciences, vol. 117, no. 30, pp. 17513-17515, 2020.

[12] Y. Fang, Y. Nie, and M. Penny, "Transmission dynamics of the covid-19 outbreak and effectiveness of government interventions: a data-driven analysis," Journal of Medical Virology, vol. 92, no. 6, pp. 645-659, 2020.

[13] H. Nishiura, N. M. Linton, and A. R. Akhmetzhanov, "Serial interval of novel coronavirus (COVID-19) infections," International Journal of Infectious Diseases, vol. 93, pp. 284-286, 2020.

[14] World Health Organization (WHO), "Criteria for releasing COVID-19 patients from isolation,” 2020, https://www.who .int/news-room/commentaries/detail/criteria-for-releasingcovid-19-patients-fromisolation.

[15] D. K. Chu, E. A. Akl, S. Duda et al., "Physical distancing, face masks, and eye protection to prevent person-to-person transmission of SARS-CoV-2 and COVID-19: a systematic review and meta-analysis," The Lancet, vol. 395, no. 10242, pp. 1973-1987, 2020.

[16] S. E. Eikenberry, M. Mancuso, E. Iboi et al., "To mask or not to mask: modeling the potential for face mask use by the general public to curtail the COVID-19 pandemic," Infectious Disease Modelling, vol. 5, pp. 293-308, 2020.

[17] A. Erath, M. Löchl, and K. W. Axhausen, "Graph-theoretical analysis of the Swiss road and railway networks over time," Networks and Spatial Economics, vol. 9, no. 3, pp. 379-400, 2009.

[18] E. Unit, "Guideline for the home quarantine / quarantine in non-health care settings," 2020, https://www.epid.gov.lk/web/ images/pdf/circulars/corona-virus/guidelines-ofhomequarantine.pdf.

[19] H. Nishiura, T. Kobayashi, T. Miyama et al., "Estimation of the asymptomatic ratio of novel coronavirus infections (COVID19)," International journal of infectious diseases, vol. 94, no. 154, pp. 154-155, 2020.

[20] L. Rivett, S. Sridhar, D. Sparkes et al., "Screening of healthcare workers for SARS-CoV-2 highlights the role of asymptomatic carriage in COVID-19 transmission," eLife, vol. 9, article e58728, 2020.

[21] Department of Census \& Statistics, "Statistic: census of population and housing 2001," 2001, http://www.statistics.gov.lk/ pophousat/pdf/housing/p10h6\%20no.\%20of\%20hh.pdf. 